\title{
Finite element analysis of wedge and biconcave deformity in four different height restoration after augmentation of osteoporotic vertebral compression fractures
}

Xiao-Hua Zuo ${ }^{1,2+}$, Yin-Bing Chen ${ }^{3 \dagger}$, Peng Xie ${ }^{4 \dagger}$, Wen-Dong Zhang ${ }^{5}$, Xiang-Yun Xue ${ }^{6}$, Qian-Xi Zhang ${ }^{2}$, Ben Shan ${ }^{7}$, Xiao-Bing Zhang ${ }^{7^{*}}$, Hong-Guang Bao ${ }^{*^{*}}$ and Yan-Na Si ${ }^{i^{*}}$

\begin{abstract}
Purpose: Biomechanical comparison of wedge and biconcave deformity of different height restoration after augmentation of osteoporotic vertebral compression fractures was analyzed by three-dimensional finite element analysis (FEA).

Methods: Three-dimensional finite element model (FEM) of T11-L2 segment was constructed from CT scan of elderly osteoporosis patient. The von Mises stresses of vertebrae, intervertebral disc, facet joints, displacement, and range of motion (ROM) of wedge and biconcave deformity were compared at four different heights (Genant 0-3 grade) after T12 vertebral augmentation.

Results: In wedge deformity, the stress of T12 decreased as the vertebral height in neutral position, flexion, extension, and left axial rotation, whereas increased sharply in bending at Genant 0; L1 and L2 decreased in all positions excluding flexion of $\mathrm{L} 2$, and $\mathrm{T} 11$ increased in neutral position, flexion, extension, and right axial rotation at Genant 0. No significant changes in biconcave deformity. The stress of T11-T12, T12-L1, and L1-L2 intervertebral disc gradually increased or decreased under other positions in wedge fracture, whereas L1-L2 no significant change in biconcave fracture. The utmost overall facet joint stress is at Genant 3, whereas there is no significant change under the same position in biconcave fracture. The displacement and ROM of the wedge fracture had ups and downs, while a decline in all positions excluding extension in biconcave fracture.

(Continued on next page)
\end{abstract}

\footnotetext{
* Correspondence: zhangxiaobing87@163.com; hongguangbaocn@sina.com; siyanna@163.com

${ }^{+}$Xiao-Hua Zuo, Yin-Bing Chen and Peng Xie contributed equally to this work.

'Department of Anesthesiology, Nanjing First Hospital, Nanjing Medical University, Nanjing 210006, China

${ }^{7}$ Department of Radiology, The Affiliated Huai'an Hospital of Xuzhou Medical

University and The Second People's Hospital of Huai'an, Huai'an 223002,

China

Full list of author information is available at the end of the article
}

C C The Author(s). 2021 Open Access This article is licensed under a Creative Commons Attribution 4.0 International License, which permits use, sharing, adaptation, distribution and reproduction in any medium or format, as long as you give appropriate credit to the original author(s) and the source, provide a link to the Creative Commons licence, and indicate if changes were made. The images or other third party material in this article are included in the article's Creative Commons licence, unless indicated otherwise in a credit line to the material. If material is not included in the article's Creative Commons licence and your intended use is not permitted by statutory regulation or exceeds the permitted use, you will need to obtain permission directly from the copyright holder. To view a copy of this licence, visit http://creativecommons.org/licenses/by/4.0/ The Creative Commons Public Domain Dedication waiver (http://creativecommons.org/publicdomain/zero/1.0/) applies to the data made available in this article, unless otherwise stated in a credit line to the data. 
(Continued from previous page)

Conclusions: The vertebral restoration height after augmentation to Genant 0 affects the von Mises stress, displacement, and ROM in wedge deformity, which may increase the risk of fracture, whereas restored or not in biconcave deformity.

Keywords: Osteoporotic vertebral compression fractures, Percutaneous vertebral augmentation, Finite element analysis, Anterior wedge deformity, Biconcave deformity

\section{Introduction}

Osteoporotic vertebral compression fractures (OVCFs) are among the most common complications of osteoporosis, a systemic bone disorder with a decline in bone mineral density and degradation skeletal microarchitecture $[1-3]$. In the population over 65 years and older, the prevalence of OVCFs is more than $30 \%$ and increases with age. OVCFs commonly afflict most elderly population resulting in pain, spinal deformity, functional incapacity, decreased quality of life, and increased mortality. OVCFs have become a more progressively severe disease and a significant health problem worldwide that would apparently increase social and economic burdens to society and family [4-8].

Progressive spinal deformity occurred, subsequent to sagittal imbalance, overload of facet joints, paraspinal muscle spasm, and occasional impingement of sympathetic nerve or spinal nerve $[9,10]$. Melton et al. divided the vertebral fracture's morphology into three types: wedge, biconcave, and crush fracture [11]. The difference in fracture type is most likely due to differences in biomechanical effects [12]. Wedge fracture is the loss of the height of the anterior vertebral, which can lead to the change of kyphosis angle, forward center of gravity, and the sagittal imbalance $[13,14]$. The biconcave fracture does not affect the kyphosis. It can directly affect the upper and lower endplates and the intervertebral disc, affecting the stress distribution. Although the crush fracture does not affect the kyphosis, it affects the stress distribution and the collapse of the posterior vertebrae resulting in reduced intervertebral foramen. Percutaneous vertebral augmentation (PVA) is a treatment for strengthening the fractured vertebrae and restoring the height of the vertebrae $[15,16]$. In patients with OVCFs, the fractured vertebral height can be completely, partially, or not restored after vertebral augmentation. The fractured vertebral collapses again after PVA in some patients, which may be related to the stress unevenness after vertebral augmentation.

In 1974, Belytschko et al. first applied FEA for biomechanical analysis in the spine [17]. At present, FEA is widely used in mechanics of spinal diseases [18-21]. Researchers have analyzed the effects of different vertebral height of OVCFs on the von Mises stress of vertebral bodies after PVA in wedge fracture [22]. Currently, little research regarding biomechanical effects of different types of vertebral deformity has been reported with von Mises stresses, displacement, and ROM by FEA. Vertebral deformity of OVCFs results in the mechanical instability of the vertebrae. Different types of fractures of OVCFs may have different biomechanics patterns. Therefore, we hypothesized that there are biomechanical differences in the recovery of vertebrae from different fracture types (wedge and biconcave fractures) in OVCFs. The present study aimed to explore the biomechanical effects between two different types of vertebral deformity with von Mises stresses, displacement, and ROM by three-dimensional (3D) FEA. By analyzing the differences of T12 wedge and biconcave deformity in four different height restoration (Genant 3, 2, 1, 0) after augmentation of OVCFs, we will determine the consistency of biomechanical results and fracture type with different vertebral height for deciding which height restoration must be performed.

\section{Methods \\ The FEA models of T11-L2 segment in elderly osteoporosis}

A 65-year-old female osteoporosis patient was selected without other abnormal findings on radiographs. After signing the informed consent, the geometry of the thoracolumbar spine was reconstructed from $0.5-\mathrm{mm}$ thick and intervals computerized tomography (CT) scans of the patient. CT scan images were processed with Mimics 16.0 (Materialise, Leuven, Belgium) and transformed into a solid model. After repair, denoise and spheroidality with Geomagic Studio 2014 (Geomagic, Morrisville, USA), and assemble with Pro/E5.0 (PTC, MA, USA), the T11-L2 thoracolumbar geometry model was then imported into the Hypermesh13.0 (Altair, California, USA) for meshing. Finite element meshing secondary processing, other tissue meshing, and analyzed were performed in MSC.Patran/Nastran2012 (MSC, USA). The FEM construct comprised vertebrae, posterior elements (including cortical and cancellous bone), intervertebral discs, endplates, anterior longitudinal ligament (ALL), posterior longitudinal ligament (PLL), capsular ligament $(\mathrm{CL})$, intertransverse ligament, ligamentum flavam (ITL), interspinous ligament (ISL), and supraspinous ligament (SSL). The four-node tetrahedral elements modeled in 
vertebrae and eight-node hexahedral elements intervertebral disc. The ligaments were assumed to be two-node nonlinear spring elements subjected only to tensile load. The surface-surface contact elements were applied to simulate facet joints, and the coefficient of friction was assigned to 0.2 [23].

\section{FEM validation}

The validation of the established FEM is crucial for utilizing a model to simulate authentic responses. The ROM data were in comparison with the results of a cadaveric biomechanical investigation [24-26] that applied a similar load (10N.M moment, $150 \mathrm{~N})$, in flexion, extension, lateral bending (left and right), and axial rotation (left and right). The FEM was validated because of the calculated ROM approximate to the literature, which indicated that the model could be implemented in the following application of OVCFs.

\section{The FEA models of T11-L2 segment in OVCFs}

According to Genant semi-quantitative method (0-3 grade), Genant $0-3$ of the T12 anterior wedge deformity and biconcave deformity were constructed respectively. Different vertebral heights of T12 vertebral body after vertebral augmentation were simulated as Genant grade. The simulation of cement filling was executed based on the knowledge related to the clinical prescription of vertebral augmentation. The geometry and distribution of the cement filling were defined as the previous study. Bone cement equivalent to $30 \%$ of vertebral volume was filled to the trabecular of T12 vertebra. Material properties of finite element analysis models are shown in Table $1[19,23]$. Figure 1 illustrates a schematic showing the location, shape, and overall size of the bone cement in the vertebrae.

\section{Loading and boundary conditions}

The multi-level FEM of T11-L2 was used for analysis. The lower surface of the L2 endplate was characterized to be rigidly anchored, and the loads were implemented on the upper surface of the T11 endplate. An axial compressive preload of $500 \mathrm{~N}$ was set, and a torsional moment of $10 \mathrm{~N} \cdot \mathrm{M}$ was dictated to imitate the motions of neutral position (NP), flexion (FLEX), extension (EXT), left lateral bending (LLB), right lateral bending (RLB), left axial rotation (LAR), and right axial rotation (RAR) [18, 27-29]. The overall displacement and ROM of T11L2 segment in four heights were investigated and compared with the two types of fracture. The peak von Mises stress on vertebrae, intervertebral disc, facet joint, and the stress distribution was also used for analysis.

\section{Results}

Comparative analysis of von Mises stress

The nephograms of the overall vertebral stress, displacement, and T12 vertebral stress are shown in Fig. 2. The von Mises stress peaks of the vertebrae intervertebral disc and facet joint shown in Fig. 3. Wedge deformity in the position of neutral position, flexion, extension, and left axial rotation, the von Mises stress of T12 decreased as the restoration height of vertebrae to Genant 3, 2, 1, and 0 , respectively, whereas increased sharply at Genant

Table 1 Material properties of finite element analysis models

\begin{tabular}{llll}
\hline Component & Young Modulus(MPa) & Poisson ratio & Cross-sectional area(mm ${ }^{2}$ ) \\
\hline Cortical bone & 8040 & 0.30 & -- \\
cancellous bone & 37 & 0.20 & -- \\
Bony end-plate & 670 & 0.40 & -- \\
Posterior structure & 2345 & 0.25 & -- \\
Fibrous annulus & 4.2 & 0.45 & -- \\
Nucleus pulposus & 0.2 & 0.49 & -- \\
Annulus matrix & 500 & 0.30 & -- \\
Cement & 3000 & 0.40 & -- \\
Articular facet cartilage & 10 & 0.40 & 57 \\
Anterior longitudinal ligament & 20 & 0.30 & 24 \\
Posterior longitudinal ligament & 70 & 0.30 & 8 \\
Supraspinous ligament & 28 & 0.30 & 28 \\
Interspinous ligament & 28 & 0.30 & 48 \\
Capsular ligament & 20 & 0.30 & 49 \\
Ligamentum flavum & 50 & 0.30 & 9 \\
Intertransverse ligament & 50 & 0.30 & \\
\hline
\end{tabular}




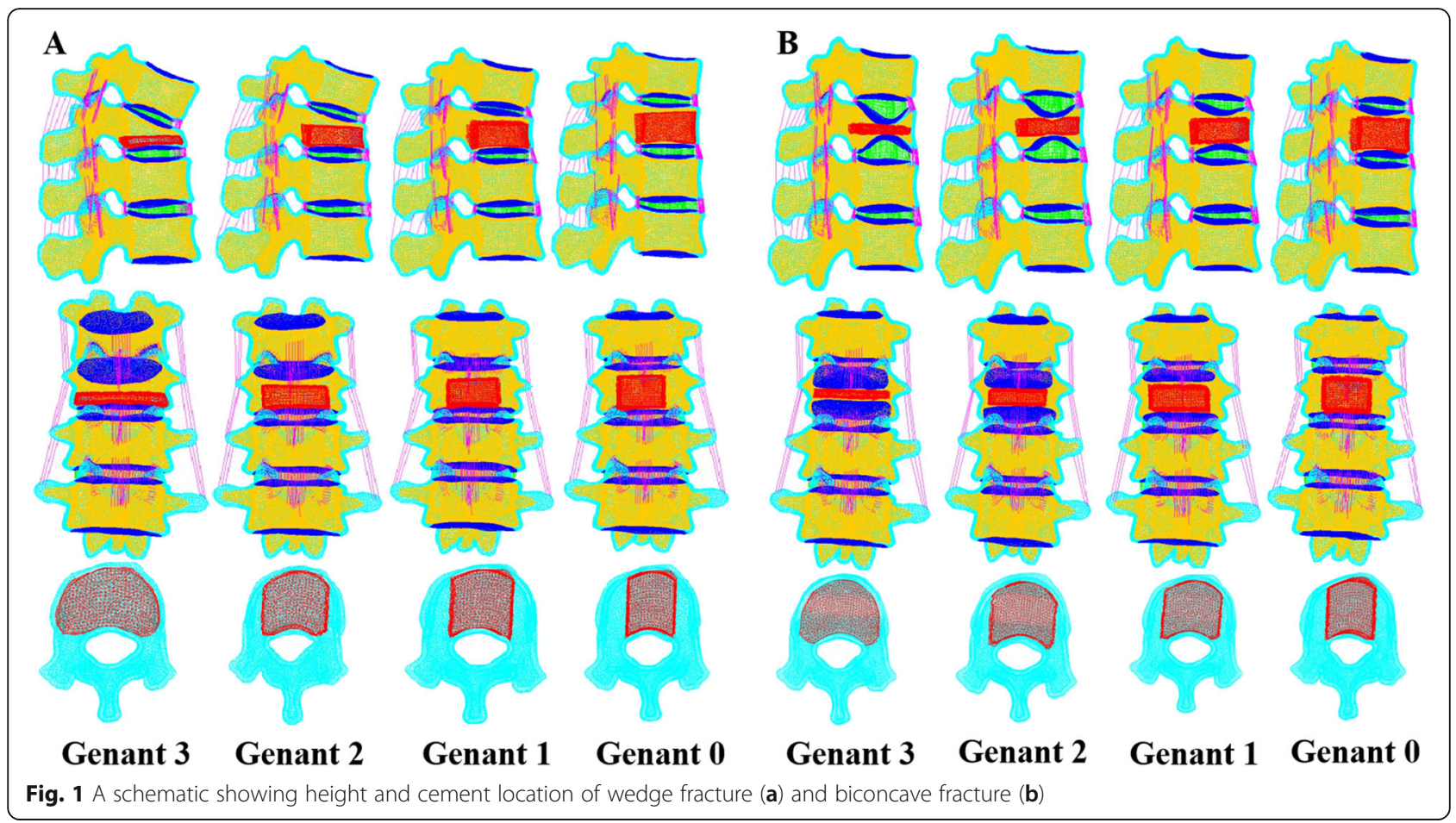

0 in lateral bending. The von Mises stress of adjacent vertebrae (L1 and L2) decreased slowly with the height of vertebrae in all positions excluding flexion of $\mathrm{L} 2$, and the stress of T11 vertebrae was increased in some positions and decreased in other positions. The stress of T11, T12, L1, and L2 vertebrae did not significantly change with the increase of recovery height in biconcave deformity.

The stress of T11-T12 intervertebral disc decreased gradually with the height in lateral bending and axial rotation position in wedge fracture, but there is no noticeable change trend in biconcave deformity. The stress of T12-L1 intervertebral disc was gradually increased with the height of vertebrae when flexion in wedge fracture, while the stress was similar under seven positions in biconcave fracture. The stress gradually decreases with the height under seven positions in biconcave fracture. The stress of L1-L2 intervertebral disc gradually increased with the height of the vertebral body under flexion in wedge fracture and decreased under neutral position, extension, right lateral bending, and axial rotation. There was no significant change with vertebral height under the same position in biconcave fracture.

The overall facet joint stress was gradually decreased in wedge fracture, and the most considerable decreased stress in flexion and the utmost stress is in all positions at Genant 3. There was no significant change in the overall facet joint stress in the same position of biconcave fracture.

\section{Comparative analysis of displacement and ROM}

The nephograms of displacement are shown in Fig. 2b. The displacement and ROM showed in Fig. 4. In wedge fracture, the overall displacement and ROM of the T11L2 vertebrae gradually increased with the vertebral height in flexion and decreased in extension, while the trend was opposite in the biconcave fracture. The displacement and ROM increased with the vertebral height, and the maximum is about $94 \%$ at Genant 0 in contrast to Genant 3 in flexion, while the extension stretched gradually, the displacement and ROM decreased most $48 \%$ at Genant 0 in the wedge fracture. The displacement and ROM increased slowly under extension in the biconcave fracture and decreased gradually in the other six positions. The displacement and ROM of the wedge fracture have increased and decreased, while decreased slowly in all positions excluding extension in biconcave fracture.

\section{Discussion}

In this study, elderly osteoporosis patient was selected, and CT data were obtained. The FEM of osteoporosis T11-L2 was successfully established and validated. Based on the above, we research on one of the frequent thoracolumbar spine fractures (T12), one of the suitable stiffness bone cement volume (equivalent to $30 \%$ of $\mathrm{T} 12$ vertebral volume), and top two fracture type (wedge and biconcave) of OVCFs [30-32]. We demonstrated whether different fracture type (wedge and biconcave) 


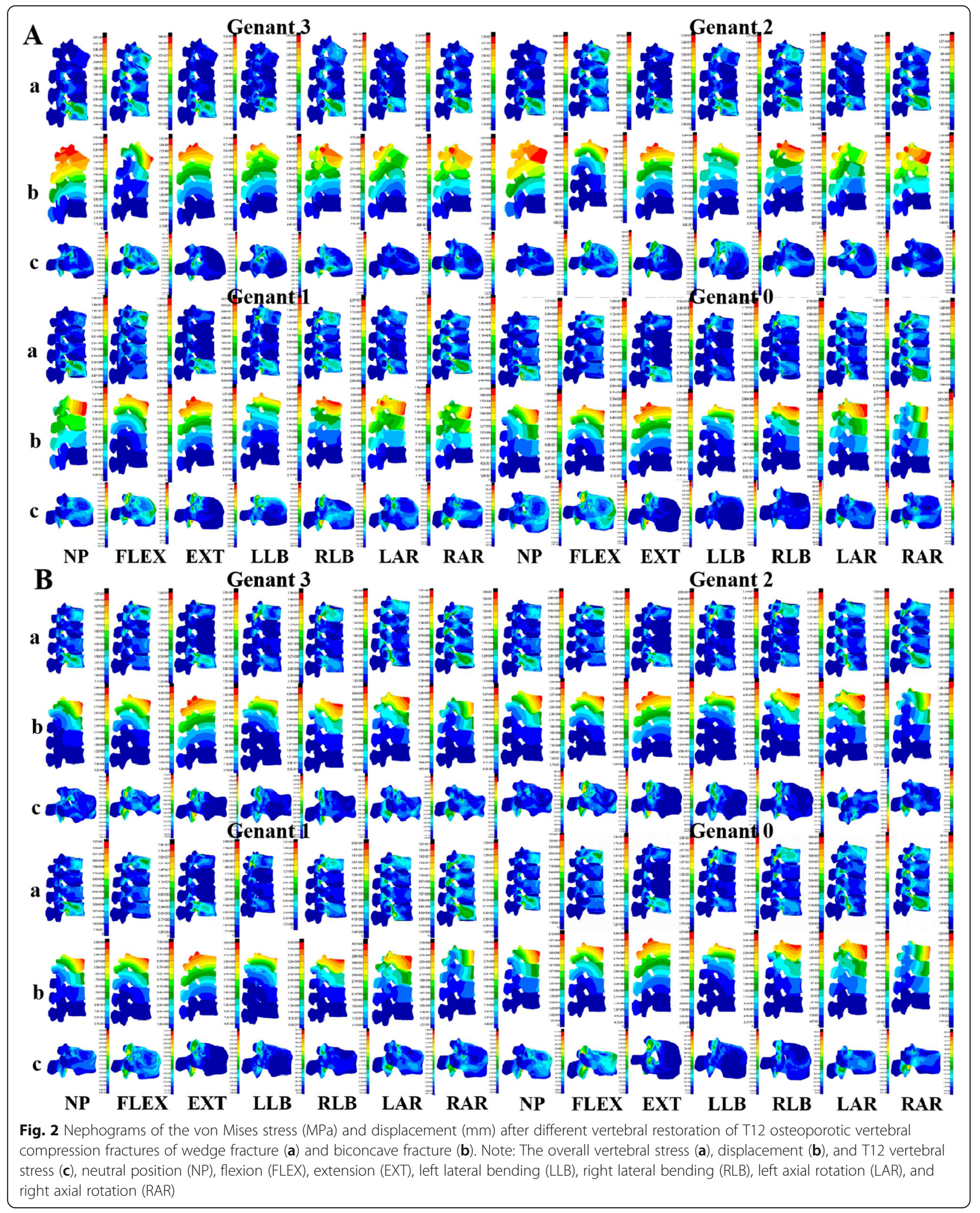



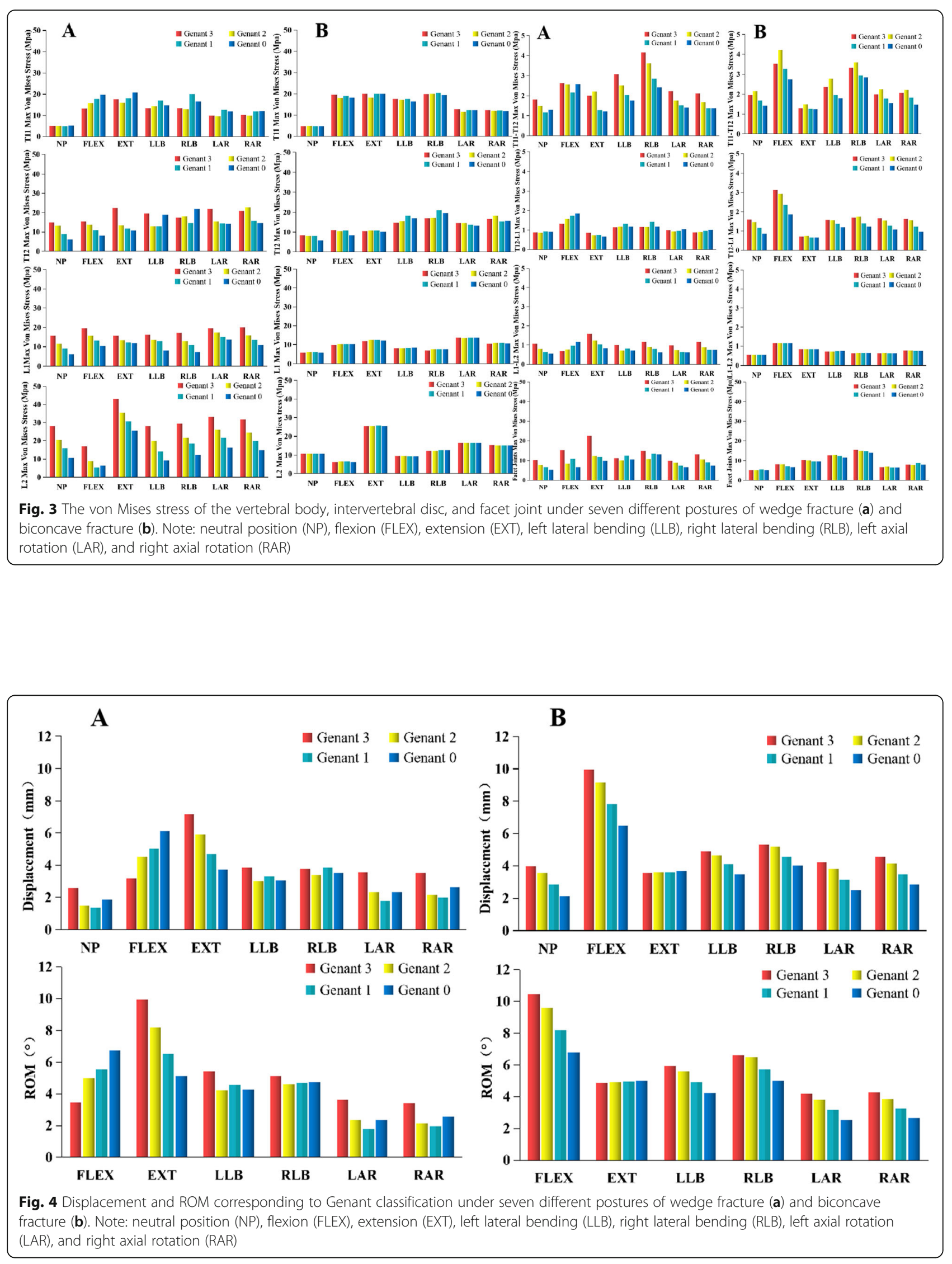
has a potentially effect on height restoration after augmentation of OVCFs. To clarify the biomechanical comparison of wedge and biconcave deformity of different height restoration after augmentation of OVCFs, we performed finite element analysis of the von Mises stresses of vertebrae, intervertebral disc, facet joints, displacement, and range of motion (ROM) of wedge and biconcave deformity were compared at four different heights (Genant 3, 2, 1, 0) after T12 vertebral augmentation. Collectively, our data demonstrated that the vertebral height after vertebral augmentation restores to Genant 0 in wedge deformity, affecting the von Mises stress, displacement, and ROM, which may increase the risk of fracture, whereas restoration height restored or not in biconcave deformity.

The vertebral morphology of OVCFs varies in shape and height. Melton et al. divided the spine fracture into three types: wedge deformity, biconcave deformity, and crush deformities [11]. The Genant visual semiquantitative method is based on the reduction in the anterior, middle, and posterior vertebral heights by lateral $\mathrm{X}$-rays. It has been widely used in clinical and epidemiological studies [3, 33-35]. OVCF patients with wedge fractures after PVA recovery of anterior vertebral can moderately improve kyphosis and center of gravity forward for restoration in sagittal imbalance and reduce the stress on the paraspinal muscles of patients with OVCFs to maintain balance [36]. Although the biconcave deformities after PVA do not affect the kyphosis and the center of gravity, it can improve the biomechanical changes of the endplates of the fractured vertebral and adjacent intervertebral discs and influence the mechanical distribution of adjacent vertebral. In this study, the stress of T12 in wedge deformity decreased as the vertebral height in neutral position, flexion, extension, and left axial rotation, whereas increased sharply in bending at Genant 0 and no significant changes in biconcave deformity. The displacement and ROM of the wedge fracture had ups and downs, while a decline in all positions excluding extension in biconcave fracture.

Some researchers have analyzed the biomechanical of the L2 fractured vertebral of OVCFs after PVA by finite element analysis, which can enhance the strength of the fractured vertebral and increase the vertebral load. In the study of patients with OVCFs, bone cements $(3,5$, and $10 \mathrm{ml}$ ) with different elastic moduli $(1800,500$, and $150 \mathrm{MPa}$ ) were injected into the $\mathrm{L} 2$ fractured vertebrae. In the neutral position, flexion and extension, lateral bending and axial rotation position, the vertebral showed similar maximum von Mises stress, and the maximum stress of the cortical bone and the lower endplate adjacent to the vertebral body L1 increased significantly. In the neutral position, flexion, extension, and lateral bending (left and right) positions, the maximum von Mises stress of the vertebral increases with the increase of the elastic modulus of the cement [37]. The finite element analysis of patients with OVCFs after PVA of T12 fractured vertebral suggests that insufficient bone cement and asymmetric distribution may lead to a maximum displacement of the vertebral body, and a significant increase in maximum von Mises stress of cancellous and cortical bone, which may lead to re-fracture of the T12 vertebral and fracture of the adjacent vertebral [38]. This finite element analysis did not study the different heights of OVCFs after PVA. Based on the FEM of T12 wedge deformity in patients with non-osteoporosis, the maximum von Mises stress of the lower endplate of T11 vertebral and the upper endplate of L1 vertebrae, and the compression of T12 anterior vertebral (compressed to $90 \%, 80 \%, 70 \%, 60 \%, 50 \%, 40 \%, 30 \%, 20 \%$, and $10 \%$ ) are positively correlated [39]. There was no significant difference between the maximum von Mises stresses of vertebral heights (Genant 3, 1, and 0) after T12 undifferentiated fracture typed OVCFs augmentation [22]. However, unlike the previous research, our study compared wedge and biconcave deformity. This difference in fracture type may account for the different result.

\section{Conclusion}

The vertebral height after vertebral augmentation restores to Genant 0 in wedge deformity, affecting the von Mises stress, displacement, and ROM, which may increase the risk of fracture, whereas restoration height restored or not in biconcave deformity.

\section{Abbreviations}

FEA: Finite element analysis; FEM: Finite element model; OVCFs: Osteoporotic vertebral compression fractures; PVA: Percutaneous vertebral augmentation; ROM: Range of motion; CT: Computerized tomography

\section{Authors' contributions}

$\mathrm{XH}$ Zuo, YB Chen, and P Xie contributed to the design and concept of the study. WD Zhang, $X Y$ Xue, and QX Zhang were responsible for the validation of the FEA model and critical recommendation for the established model. XB Zhang and B Shan were responsible for data analysis and interpretation. All authors contributed to the writing and critical revisions for intellectual content and final approval of the article.

\section{Funding}

This study was funded by the National Natural Science Foundation of China (No. 81873954).

\section{Availability of data and materials \\ The datasets used and/or analyzed during the current study are available from the corresponding author on reasonable request.}

\section{Ethics approval and consent to participate}

This study has been reviewed by the appropriate ethics committee of our hospital and has been performed in accordance with the ethical standards laid down in an appropriate version of the 1964 Declaration of Helsinki.

Consent for publication

Not applicable.

Competing interests

All authors declare that they have no competing interests. 


\section{Author details}

'Department of Anesthesiology, Nanjing First Hospital, Nanjing Medical University, Nanjing 210006, China. ${ }^{2}$ Department of Pain Management, The Affiliated Huai'an Hospital of Xuzhou Medical University and The Second People's Hospital of Huai'an, Huai'an 223002, China. ${ }^{3}$ Department of Orthopedic Surgery, The Affiliated Haian Hospital of Nantong University, Haian 226600, China. ${ }^{4}$ Department of Neurosurgery, The Affiliated Huai'an Hospital of Xuzhou Medical University and The Second People's Hospital of Huai'an, Huai'an 223002, China. ${ }^{5}$ Department of Orthopedics, Northern Jiangsu People's Hospital, Yangzhou 225001, China. ${ }^{6}$ Department of Pain Management, Yancheng No.1 People's Hospital, Yancheng 224000, China. ${ }^{7}$ Department of Radiology, The Affiliated Huai'an Hospital of Xuzhou Medical University and The Second People's Hospital of Huai'an, Huai'an 223002 China

Received: 24 June 2020 Accepted: 11 January 2021

Published online: 15 February 2021

\section{References}

1. Achatz G, Riesner H, Friemert B, Lechner R, Graf N, Wilke H. Biomechanical in vitro comparison of radiofrequency kyphoplasty and balloon kyphoplasty. Eur Spine J. 2017:26(12):3225-34.

2. Zuo XH, Zhu XP, Bao HG, et al. Network meta-analysis of percutaneous vertebroplasty, percutaneous kyphoplasty, nerve block, and conservative treatment for nonsurgery options of acute/subacute and chronic osteoporotic vertebral compression fractures (OVCFs) in short-term and long-term effects. Medicine (Baltimore). 2018;97(29):e11544.

3. Cai S, Yu H, Li Y, et al. Bone mineral density measurement combined with vertebral fracture assessment increases diagnosis of osteoporosis in postmenopausal women. Skeletal Radiol. 2020;49(2):273-80.

4. Zhao JG, Zeng XT, Wang J, Liu L. Association between calcium or vitamin D supplementation and fracture incidence in community-dwelling older adults: a systematic review and meta-analysis. JAMA. 2017;318(24):2466-82.

5. Oden A, McCloskey EV, Kanis JA, Harvey NC, Johansson H. Burden of high fracture probability worldwide: secular increases 2010-2040. Osteoporos Int. 2015;26(9):2243-8

6. Zhang L, Zhai P. A comparison of percutaneous vertebroplasty versus conservative treatment in terms of treatment effect for osteoporotic vertebral compression fractures: a meta-analysis. Surg Innov. 2020;27(1):1925

7. Ma Y, Wu X, Xiao $X$, et al. Effects of teriparatide versus percutaneous vertebroplasty on pain relief, quality of life and cost-effectiveness in postmenopausal females with acute osteoporotic vertebral compression fracture: a prospective cohort study. Bone. 2020;131:115154

8. Cao Z, Wang G, Hui W, Liu B, Liu Z, Sun J. Percutaneous kyphoplasty for osteoporotic vertebral compression fractures improves spino-pelvic alignment and global sagittal balance maximally in the thoracolumbar region. Plos One. 2020:15(1):e228341.

9. Zhang YL, Shi LT, Tang PF, Sun ZJ, Wang YH. Correlation analysis of osteoporotic vertebral compression fractures and spinal sagittal imbalance. Orthopade. 2017:46(3):249-55.

10. Wilson DJ, Owen S, Corkill RA. Facet joint injections as a means of reducing the need for vertebroplasty in insufficiency fractures of the spine. Eur Radiol. 2011:21(8):1772-8.

11. Melton L, Lane AW, Cooper C, Eastell R, O'Fallon WM, Riggs BL. Prevalence and incidence of vertebral deformities. Osteoporos Int. 1993;3(3):113-9.

12. Jiang W, Li X, Cheng K, Wang C, Cheng X. Study of the types of osteoporotic vertebral fractures and the difference of volumetric BMD detected using QCT. Chin J Osteoporos. 2014;20(11):1273-5.

13. Kanayama M, Oha F, Iwata A, Hashimoto T. Does balloon kyphoplasty improve the global spinal alignment in osteoporotic vertebral fracture? Int Orthop. 2015;39(6):1137-43.

14. Gupta A, Upadhyaya S, Cha T, Schwab J, Bono C, Hershman S. Serum albumin levels predict which patients are at increased risk for complications following surgical management of acute osteoporotic vertebral compression fractures. Spine J. 2019;19(11):1796-802

15. Ye $L Q$, Liang $D$, Jiang $X B$, et al. Risk factors for the occurrence of insufficient cement distribution in the fractured area after percutaneous vertebroplasty in osteoporotic vertebral compression fractures. Pain Physician. 2018:21(1): E33-42.
16. Wang B, Zhao CP, Song LX, Zhu L. Balloon kyphoplasty versus percutaneous vertebroplasty for osteoporotic vertebral compression fracture: a metaanalysis and systematic review. J Orthop Surg Res. 2018;13(1):264.

17. Belytschko T, Kulak RF, Schultz AB, Galante JO. Finite element stress analysis of an intervertebral disc. J Biomech. 1974;7(3):277-85.

18. Adler D, Akbar M, Spicher A, Goerke SA, Schmoelz W. Biomechanical study of a novel, expandable, non-metallic and radiolucent CF/PEEK vertebral body replacement (VBR). Materials (Basel). 2019;12(17):2732.

19. Wang D, Li Y, Yin H, et al. Three-dimensional finite element analysis of optimal distribution model of vertebroplasty. Ann Palliat Med. 2020;9(3): 1062-72

20. McKay M, Jackman TM, Hussein Al, Guermazi A, Liu J, Morgan EF. Association of vertebral endplate microstructure with bone strength in men and women. Bone. 2020;131:115147.

21. Robinson DL, Tse KM, Franklyn M, Ackland DC, Richardson M, Lee P. Occlusion of the lumbar spine canal during high-rate axial compression. Spine J. 2020:20(10):1692-704.

22. Zhao WT, Qin DP, Zhang XG, Wang ZP, Tong Z. Biomechanical effects of different vertebral heights after augmentation of osteoporotic vertebral compression fracture: a three-dimensional finite element analysis. J Orthop Surg Res. 2018;13(1):32

23. Polikeit A, Nolte LP, Ferguson SJ. The effect of cement augmentation on the load transfer in an osteoporotic functional spinal unit: finite-element analysis. Spine (Phila Pa 1976). 2003;28(10):991-6.

24. Su Y, Wang X, Ren D, Liu Y, Liu S, Wang P. A finite element study on posterior short segment fixation combined with unilateral fixation using pedicle screws for stable thoracolumbar fracture. Medicine (Baltimore). 2018; 97(34):e12046.

25. Pflugmacher R, Schleicher $P$, Schaefer J, et al. Biomechanical comparison of expandable cages for vertebral body replacement in the thoracolumbar spine. Spine (Phila Pa 1976). 2004;29(13):1413-9.

26. Li C, Zhou Y, Wang H, Liu J, Xiang L. Treatment of unstable thoracolumbar fractures through short segment pedicle screw fixation techniques using pedicle fixation at the level of the fracture: a finite element analysis. Plos One. 2014;9(6):e99156

27. Costa MC, Eltes P, Lazary A, Varga PP, Viceconti M, Dall'Ara E. Biomechanical assessment of vertebrae with lytic metastases with subject-specific finite element models. J Mech Behav Biomed Mater. 2019:98:268-90.

28. Lu Q, Liu C, Wang D, Liu H, Yang H, Yang L. Biomechanical evaluation of calcium phosphate-based nanocomposite versus polymethylmethacrylate cement for percutaneous kyphoplasty. Spine J. 2019;19(11):1871-84.

29. Bassani T, Casaroli G, Galbusera F. Dependence of lumbar loads on spinopelvic sagittal alignment: An evaluation based on musculoskeletal modeling. Plos One. 2019;14(3):e207997.

30. Kim J, Shin DA, Byun D, Kim H, Kim S, Kim H. Effect of bone cement volume and stiffness on occurrences of adjacent vertebral fractures after vertebroplasty. J Korean Neurosurg S. 2012:52(5):435-40.

31. Özger Ö, Kaplan N. Clınıcal results of percutaneous vertebroplasty in thoracolumbar (T6-L5) vertebral compression fractures: retrospective study of 111 patients with 140 fractured segments. J Turk Spinal Surg. 2019;30(3): 199-205.

32. Shetty S, John B, Mohan S, Paul TV. Vertebral fracture assessment by dualenergy $\mathrm{X}$-ray absorptiometry along with bone mineral density in the evaluation of postmenopausal osteoporosis. Arch Osteoporos. 2020;15(1):25.

33. Pongchaiyakul C, Charoensri S, Leerapun T, Wongsiri S, Songpatanasilp T, Taechakraichana N. Prevalence of asymptomatic radiographic vertebral fracture in postmenopausal Thai women. Arch Osteoporos. 2020;15(1):78.

34. Wáng Y, Diacinti D, Yu W, et al. Semi-quantitative grading and extended semi-quantitative grading for osteoporotic vertebral deformity: a radiographic image database for education and calibration. Ann Transl Med. 2020;8(6):398.

35. Ma J, Siminoski K, Wang $P$, et al. The accuracy of prevalent vertebral fracture detection in children using targeted case-finding approaches. J Bone Miner Res. 2020;35(3):460-8.

36. Yan YB, Qi W, Wu ZX, Qiu TX, Teo EC, Lei W. Finite element study of the mechanical response in spinal cord during the thoracolumbar burst fracture. Plos One. 2012;7(9):e41397

37. Cho AR, Cho SB, Lee JH, Kim KH. Effect of augmentation material stiffness on adjacent vertebrae after osteoporotic vertebroplasty using finite element analysis with different loading methods. Pain Physician. 2015;18(6):E1101-10. 
38. Liang $D$, Ye $L Q$, Jiang $X B$, et al. Biomechanical effects of cement distribution in the fractured area on osteoporotic vertebral compression fractures: a three-dimensional finite element analysis. J Surg Res. 2015;195(1):246-56.

39. Feng J, Yin $\mathrm{H}$, Chen $\mathrm{W}$, Huang M. Finite element analysis of stress of the adjacent vertebral end plate of T12 vertebral body in different compression states. Chin J Tissue Eng Res. 2016;20(22):3263-71.

\section{Publisher's Note}

Springer Nature remains neutral with regard to jurisdictional claims in published maps and institutional affiliations.

Ready to submit your research? Choose BMC and benefit from:

- fast, convenient online submission

- thorough peer review by experienced researchers in your field

- rapid publication on acceptance

- support for research data, including large and complex data types

- gold Open Access which fosters wider collaboration and increased citations

- maximum visibility for your research: over $100 \mathrm{M}$ website views per year

At $\mathrm{BMC}$, research is always in progress.

Learn more biomedcentral.com/submissions 